\title{
Incidental en-caul hydrops fetalis due to trauma: Interdisciplinary continuity of care
}

\author{
Jonathan Warren Meadows ${ }^{1 *}$ and Samuel F Brown ${ }^{2}$ \\ ${ }^{1}$ Associate member, New York Academy of Medicine, USA \\ ${ }^{2}$ Department of Obstetrics and Gynecology, Jackson Hinds Comprehensive health center, USA
}

\begin{abstract}
Background: Non-immune hydrops fetalis due to Turner syndrome is characterized by hydrops fetalis, cystic hygroma, ascites and eventual fetal demise in most cases.

Case: We report on a patient with incidental non-immune hydrops fetalis due to Turner syndrome presenting with hydrops fetalis and ascites on ultrasound, a rare en-caul vaginal delivery, and cystic hygroma, confirmed by cell-free DNA chromosomal analysis.
\end{abstract}

Conclusion: This rare case illustrates the adaptive patient management and interdisplinary coordination of care.

\section{Learning points}

1. Emergency department/acute care department work up for pregnant patients should include transabdominal pelvic ultrasound, blood type and screen consideration of RhoGam administration and proper referral to specialist (such as obstetric/gynecology and/ or high-risk pregnancy evaluation with Maternal Fetal Medicine).

2. $\mathrm{Rh}(\mathrm{D})$ immune globulin has proportionately decreased cases of immune hydrops fetalis due to red cell alloimmunization, leading to non-immune hydrops fetalis (NIHF) accounting for $90 \%$ of hydrops fetalis cases.

3. NIHF has a reported prevalence of 1 in 1,700-3,000 pregnancies; its etiologies are numerous and include the following: cardiovascular abnormalities, chromosomal abnormalities and fetal anemia.

4. This NIHF case is associated with de novo aneuploidy of Turner Syndrome and warrants continued follow-up with Maternal Fetal Medicine for future pregnancies.

5. En-caul births are extremely rare (1 in 80,000 live births) and surgical en-caul births of premature infants have been reported.

\section{Introduction}

Non-immune hydrops fetalis (NIHF) has a reported prevalence of 1 in 1700-3000 pregnancies [1]. NIHF etiologies are numerous and include the following: cardiovascular abnormalities, chromosomal abnormalities and fetal anemia. Chromosomal etiologies, serving as the second most common cause, account for approximately $13 \%$ of cases and $50-70 \%$ of early pregnancies [2,3]. Monosomy X Turner syndrome $(45, \mathrm{XO})$ can account for $20 \%$ in these early conceptus losses [3]. We report on a case of incidental NIHF with monosomy X Turner syndrome due to trauma.

\section{Case report}

A 31-year-old G7P6 mother had an uncomplicated pregnancy, as indicated by regular visits, normal vaginal "spotting", and a normal first trimester ultrasound, until she tripped and fell during the preceding day as per emergency department documentation on gestational age (GA) 17.5. The patient reported abdominal pain, tightness, and peach-colored vaginal discharge. A transabdominal pelvic ultrasound revealed a singleton pregnancy, posterior placenta, FHR 135 BPM, prominent cystic spaces along the side of the fetal head and abdomen, with tissue septation and thickening (Figure 1) and abdominal ascites (Figure 2). Follow-up with maternal fetal medicine occurred four days later and transvaginal pelvic ultrasound revealed fetal demise and subsequent free fetal DNA chromosomal analysis from maternal blood was performed.

The patient was admitted to labor and delivery the next day. Past medical history included chronic hypertension and adult-onset diabetes. She admitted to taking only prenatal vitamins. The patient denied fetal movement and admitted to contractions and passing dark red clots. Last menstrual period was 10/30/2018. Previous pregnancies were normal except for one preterm delivery at 33 weeks due to probable preeclampsia at 38 weeks. All children were otherwise healthy. Gynecological history was only remarkable for two abnormal pap smears due to HPV and the lesions underwent excision. Immunizations were current. No surgical history and drug allergies were noted. She denied family history of birth defects, mental retardation, genetic abnormalities, diabetes, renal disease, heart conditions, as well as animal exposure, recent travel, and exposure to sick contacts. Vitals and physical exam was unremarkable. Prenatal labs were unremarkable (Table 1).

*Correspondence to: Jonathan Warren Meadows, Associate member, New York Academy of Medicine, USA, E-mail: Jonathan.meadows.do@gmail.com

Key words: nonimmune hydrops, cystic hygroma, turner syndrome, ascites, trauma, en-caul delivery

Received: February 16, 2021; Accepted: February 23, 2021; Published: February 26,2021 
Fetal delivery occurred "en-caul" on hospital day 1 at GA 18.3 (Figure 3). No patient complications were observed. The conceptus was female, $223 \mathrm{gm}$, grossly edematous with a cystic hygroma note on visual examination. No syndactyly, nuchal cord, meningomyelocele, and spina bifida were visualized; genitals appeared male. Placental

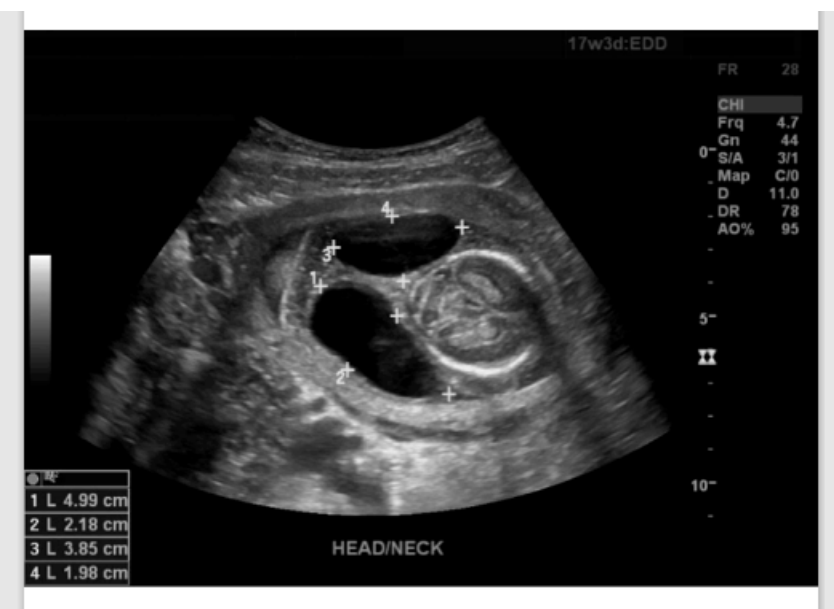

Figure 1. Transabdominal pelvic ultrasound indicating cephalic cystic spaces

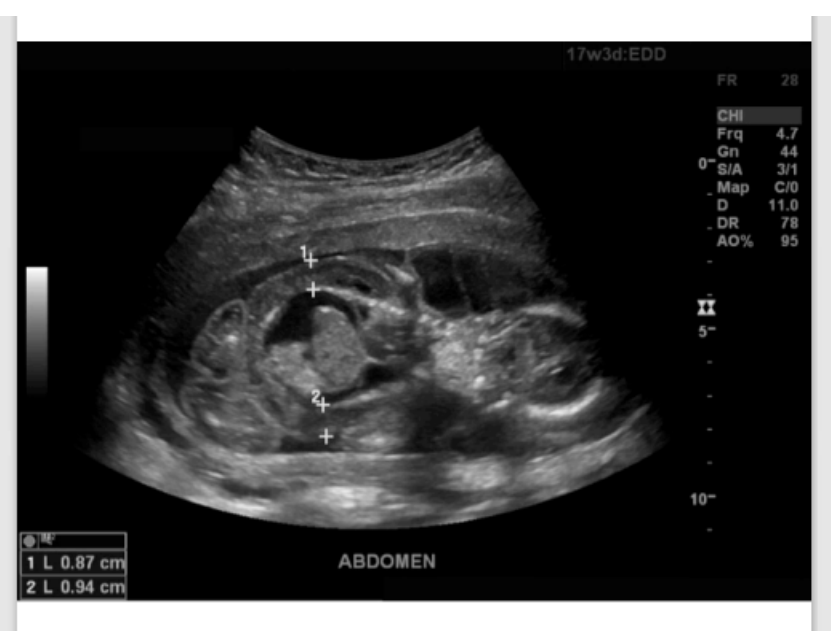

Figure 2. Transabdominal pelvic ultrasound indicating abdominal ascites

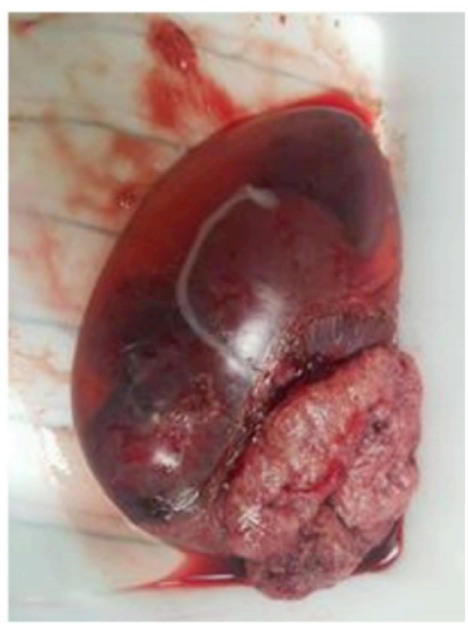

Figure 3. En-caul conceptus
Table 1. Admission laboratory tests

\begin{tabular}{|c|c|c|c|}
\hline Study & Positive & Negative & Interpretation \\
\hline Urinalysis & & Indicated & $\begin{array}{c}\text { No urinary tract } \\
\text { infection, no } \\
\text { proteinuria }\end{array}$ \\
\hline TSH & 0.160 & - & Unremarkable \\
\hline HPV & - & Indicated & Negative \\
\hline Trichomoniasis NAA & - & Indicated & Negative \\
\hline Gonococcus NAA & - & Indicated & Negative \\
\hline Chlamydia NAA & - & Indicated & Negative \\
\hline $\begin{array}{c}\text { HIV } 4^{\text {th }} \text { Gen w/ } \\
\text { Reflex }\end{array}$ & - & Indicated & Negative \\
\hline RPR & - & Indicated & Negative \\
\hline Rubella IgG & 1.34 & - & Immune \\
\hline HepB Surface Ab & - & Indicated & Negative \\
\hline $\begin{array}{c}\text { ABO type/D }(\mathrm{Rh}) \\
\text { antigen }\end{array}$ & - & - & O/ D+ \\
\hline Antibody screen & - & - & Negative \\
\hline WBC & 7.6 & - & No leukocytosis \\
\hline Hgb/MCHC/RBC & $10.7 / 30.6 / 3.74$ & - & Mild iron deficiency \\
anemia
\end{tabular}

Table 2. Available post-partum maternal laboratory tests

\begin{tabular}{|l|c|c|c|}
\hline Study & Positive & Negative & Interpretation \\
\hline Adenovirus Ab & $1: 64$ & - & Prior infection \\
\hline Coxsackie A7, A9, A16, and A24 & IgG & - & Prior infection \\
\hline Coxsackie A7, A9, A16, and A24 & - & IgM & No current infection \\
\hline Coxsackie B1, B2, B3, B4, B5, and B6 & IgG & - & Prior infection \\
\hline HSV 1 & IgG 38.7 & - & Prior infection \\
\hline HSV 2 & IgG 6.44 & - & - \\
\hline HSV 1 and 2 & - & IgM & No current infection \\
\hline Parvovirus Ab IgG & 2.8 & - & Prior infection \\
\hline Parvovirus Ab IgM & 0.1 & - & No current infection \\
\hline VZV & 563 & - & Immune \\
\hline Lyme Total Abs Serum & $<0.91$ & - & Negative \\
\hline Lyme IgM & $<0.80$ & - & Negative \\
\hline Leptospira Ab & - & Non-reactive & Negative \\
\hline Toxoplasma Gond IgM & $<3.0$ & - & No current infection \\
\hline Toxoplasma Gond IgG & $<3.0$ & - & No prior infection \\
\hline CMV IgM & $<30.0$ & - & No current infection \\
\hline Syphilis Ab & - & Indicated & Negative \\
\hline Sickle cell with Reflex & - & Indicated & Negative \\
\hline Hgb-HgbA & $97.9 \%$ & - & - \\
\hline Hgb-HgbA & $2.1 \%$ & - & - \\
\hline Hgb-HgbS & $0 \%$ & - & - \\
\hline Hgb-HgbC & $0 \%$ & - & - \\
\hline Hgb-HgbF & $0 \%$ & - & Negative \\
\hline Kleihauer-Betke Smear & - & Indicated & Monosomy X \\
\hline Direct Coombs & - & Indicated & - \\
\hline Free Fetal DNA Chromosomal Analysis & Pos & - & \\
\hline & & & - \\
\hline
\end{tabular}

gross visual examination was notable for extensive calcifications; no retroplacental hematoma, acute chorioamnionitis, chronic placentitis was noted. The placental pathology report was consistent with hydrops and edema, indicated by scant blood clots and edematous or vacuolated macrophagic Hofbauer cells.

Postpartum work up was limited by patient preference. Fetal autopsy was declined. Additional maternal serum laboratory tests were collected, and available results are reported (Table 2).

The aforementioned chromosomal analysis confirmed monosomy $\mathrm{X}$ Turner syndrome. Upon discharge, vitals and physical exam 
remained unremarkable. After discharge, the patient returned for an unremarkable two-week follow-up exam, where the patient was counseled about future pregnancies, and was scheduled for an annual examination.

\section{Discussion and conclusion}

With the advent of $\mathrm{Rh}(\mathrm{D})$ immune globulin, immune hydrops fetalis due to red cell alloimmunization has decreased and increased NIHF to account for $90 \%$ of hydrops fetalis cases [4]. More than $99 \%$ of cases of turner syndrome are fatal, with the presence of a cystic hygroma associated with impending mortality [5,6]. 50-80\% of cystic hygromas are caused by turner syndrome [7]. A cystic hygroma is described as a fluid-filled venolymphatic malformed sac from the posterior neck and is typically diagnosed in the first trimester. Lymph fails to drain from the head into the jugular vein and accumulates into the jugular lymphatic sacs [6]. Prevalence estimates of NIFH categories can be difficult without chromosomal analysis since turner syndrome cases can have chromosomal and lymphatic dysplasia categorizations, as indicated in this case given the presentation of ascites on ultrasound and the chromosomal aberration after fetal demise [2]. Furthermore, placental findings are consistent with available literature regarding Turner syndrome [8]. Typically, these cases are de novo aneuploidy in the conceptus with the parent's karyotype being normal which is supported by the patient's denial of any familial genetic or congenital abnormalities or complications in prior pregnancies [3]. Risk factors in this case include advancing age and grand multiparity.

Standard prenatal diagnostics were provided to the patient in the first trimester, such confirmatory US for estimated delivery date and nuchal translucency at 10-13 weeks. Second trimester prenatal diagnostics typically include the quadruple screening test in weeks 1522 and is best between weeks 15-18, which includes alpha fetal protein (AFP), total hCG, unconjugated estriol (uE3), and inhibin A in an integrated manner. Pregnancy-associated plasma protein (PAPP-A) is also included. This was scheduled 3-4 weeks from the obstetric visit follow up on GA 15.2 per the patient preference. Five days into the $18^{\text {th }}$ week, the patient experienced trauma and an emergency department ultrasound was performed, which revealed the hydrops and initiated deviation from the standard pathway, indicating high-risk pregnancy evaluation with Maternal Fetal Medicine.

Maternal serum and amniotic fluid marker concentrations may provide some prognostic information about Turner syndrome pregnancies. $\beta$-human chorionic gonadotropin (hCG) or AF alphafetoprotein (AFP) has a relative obstetric outcome risk of 10.667 (P = 0.0004; 95\% CI: $1.554-73.203)$ and 2.19 (P = 0.0256; 95\% CI: $1.001-$ 4.779) respectively in a limited study of 73 pregnant women [9]. Given the association of lymphatic dysplasia with Turner syndrome, other genetic mutations can share clinical presentations include the following and should be considered in genetic analysis: (1) deletion of V205 in the G protein-coupled receptor, Calcitonin Receptor-Like Receptor (hCALCRL), (2) heterozygous variants in the PIEZO1 gene, and to a lesser degree, (3) CCBE1 mutations [10-15]. Appropriate modification of the clinical evaluation and workup created coordination of patient care between acute care physicians and obstetrician/ gynecologists can optimize perinatal care and management of the patient and the current conceptus as well as counseling regarding future pregnancies.

\section{Declaration of interest}

The authors report no conflicts of interest. The authors alone are responsible for the content and writing of the paper.

\section{References}

6. Society for Maternal-Fetal Medicine (SMFM) (2015) Society for maternal-fetal medicine (SMFM) clinical guideline \#7: nonimmune hydrops fetalis. Am J Obstet Gynecol 212: 127-139. [Crossref]

7. Bellini C, Donarini G, Paladini D, Calevo MG, Bellini T, et al. (2015) Etiology of nonimmune hydrops fetalis: An update. Am J Med Genet Part A 167: 1082-1088. [Crossref]

8. Romero ST, Geiersbach KB, Paxton CN, Rose NC, Schisterman EF, et al. (2015) Differentiation of genetic abnormalities in early pregnancy loss. Ultrasound Obstet Gynecol 45: 89-94. [Crossref]

9. Santolaya J, Alley D, Jaffe R, Warsof SL (1992) Antenatal classification of hydrops fetalis. Obstet Gynecol 79: 256-259. [Crossref]

10. Urbach A, Benvenisty N (2009) Studying early lethality of 45,XO (Turner's syndrome) embryos using human embryonic stem cells. PLoS One 4: e4175. [Crossref]

11. Cunningham FG, Leveno KJ, Bloom SL, et al. (2018) Genetics. In: Cunningham FG, Leveno KJ, Bloom SL, et al., eds. Williams Obstetrics. 25e ed. New York, NY: McGraw-Hill Education.

12. Alpman A, Cogulu O, Akgul M, Arikan EA, Durmaz B, et al. (2009) Prenatally diagnosed turner syndrome and cystic hygroma: Incidence and reasons for referrals. Fetal Diagn Ther 25: 58-61. [Crossref]

13. Grapsa D, Mavrigiannaki P, Kleanthis C, Hasiakos D, Vitoratos N, et al. (2012) Autopsy findings in fetuses with cystic hygroma: a literature review and our center's experience. Clin Exp Obstet Gynecol 39: 369-373.

14. Alvarez-Nava F, Soto M, Lanes R, Pons H, Morales-Machin A, et al. (2015) Elevated second-trimester maternal serum $\beta$-human chorionic gonadotropin and amniotic fluid alpha-fetoprotein as indicators of adverse obstetric outcomes in fetal Turner syndrome. J Obstet Gynaecol Res 41: 1891-1898. [Crossref]

15. Mackie DI, Al Mutairi F, Davis RB, Kechele DO, Nielsen NR, et al. (2018) hCALCRL mutation causes autosomal recessive nonimmune hydrops fetalis with lymphatic dysplasia. J Exp Med 215: 2339-2353. [Crossref]

16. Fotiou E, Martin-Almedina S, Simpson MA, Lin S, Gordon K,et al. (2015) Nove mutations in PIEZO1 cause an autosomal recessive generalized lymphatic dysplasia with non-immune hydrops fetalis. Nat Commun 6: 8085. [Crossref]

17. Lukacs V, Mathur J, Mao R, Bayrak-Toydemir P, Procter M, et al. (2015) Impaired PIEZO1 function in patients with a novel autosomal recessive congenital lymphatic dysplasia. Nat Commun 6: 8329. [Crossref]

18. Datkhaeva I, Arboleda VA, Senaratne TN, Nikpour G, Meyerson C, et al. (2018) Identification of novel PIEZO1 variants using prenatal exome sequencing and correlation to ultrasound and autopsy findings of recurrent hydrops fetalis. Am J Med Genet Part A 176: 2829-2834. [Crossref]

19. Connell F, Kalidas K, Ostergaard P, Brice G, Murday V, et al. (2012) CCBE1 mutations can cause a mild, atypical form of generalized lymphatic dysplasia but are not a common cause of non-immune hydrops fetalis. Clin Genet 81: 191-197. [Crossref]

20. Shah S, Conlin LK, Gomez L, Aagenaes O, Eiklid K, et al. (2013) CCBE1 mutation in two siblings, one manifesting lymphedema-cholestasis syndrome, and the other, fetal hydrops. PLoS One 8: e75770. [Crossref]

Copyright: (C2021 Meadows JW. This is an open-access article distributed under the terms of the Creative Commons Attribution License, which permits unrestricted use, distribution, and reproduction in any medium, provided the original author and source are credited. 